\title{
ТЕМА ИЕРАРХИИ ПРИРОДНОГО СУЩЕГО В ПАЛАМИТСКОЙ ЛИТЕРАТУРЕ. Ч. 2. ПАЛАМИТСКОЕ УЧЕНИЕ В КОНТЕКСТЕ ПРЕДШЕСТВУЮЩЕЙ ВИЗАНТИЙСКОЙ ТРАДИЦИИ И ЕГО РЕЦЕПЦИЯ В РУССКОЙ РЕЛИГИОЗНОЙ МЫСЛИ ХХ В. (ФИЛОСОФИЯ ТВОРЧЕСТВА С.Н. БУЛГАКОВА) ${ }^{1}$
}

\author{
Taxonomies of Beings in the Palamite Literature. \\ Part 2. The Palamite Doctrine in the Context of the Previous Byzantine \\ Tradition and Its Reception in the Russian Religious Thought of the XX \\ Century (the Philosophy of Creativity by Sergei Bulgakov)
}

\section{Dmitry Biriukov}

DOI: 10.17846/CL.2019.12.2.69-79

\begin{abstract}
BIRIUKOV, Dmitry. Taxonomies of Beings in the Palamite Literature. Part 2. The Palamite Doctrine in the Context of the Previous Byzantine Tradition and Its Reception in the Russian Religious Thought of the XXth Century (the Philosophy of Creativity by Sergei Bulgakov). I provide a detailed comparison of the teaching of taxonomy of beings in Gregory Palamas and such previous Byzantine theologians as Dionysius the Areopagite and Gregory of Nyssa. I examine David Dishypatos' teaching on taxonomy of beings as well. I observe the reception of Gregory Palamas' teaching of taxonomy of beings in Russian religious and philosophical thought. In this regard, I consider Sergei Bulgakov's philosophy of creativity.
\end{abstract}

Keywords: Gregory Palamas, David Dishypatos, Sergei Bulgakov, taxonomy of beings, participation, energies, essence, Palamism, creativity

Abstrakt: BIRIUKOV, Dmitry. Taxonómie bytostí v palamitskej literatúre. Druhá čast. Palamitská doktrína $v$ kontexte byzantskej tradície a jej recepcie $v$ ruskom náboženskom myslení 20. storočia (filozofia stvorenia Sergeja Bulgakova). Článok prináša podrobné porovnanie doktríny taxonómie bytostí Gregora Palamasa a skorších byzantských teológov Dionýzia Areopagitu a Gregora z Nyssy. Na tomto základe je následne skúmaná doktrína taxonómie bytostí Davida Disipata. Text popisuje recepciu doktríny Gregora Palamasa, ktorá sa vztahuje na taxonómiu bytostí, v ruskom náboženskom a filozofickom myslení. V tomto smere sa prejednáva aj filozofia kreativity Sergeja Bulgakova.

Klúčové slová: Gregor Palamas, Dávid Dishypatos, Sergej Bulgakov, taxonómie bytostí, participácia, energie, podstata (esencia), Palamizmus, kreativita

Исследование выполнено при поддержке Российского научного фонда, проект № 18-18-00134, «Наследие византийской философии в русской и западноевропейской философии XX - XXI вв.». 
В первой части данной статьи ${ }^{2}$ сначала были кратко очерчены положения моих предыдущих исследований темы иерархии природного сущего в патристической мысли; затем был рассмотрен исторический контекст появления темы иерархии природного сущего в паламитской литературе; было описано учение Григория Паламы о двух видах Божественных энергий: боготворящей и творящей энергиях; было выявлено и описано учение Паламы об иерархии природных способностей тварного сущего, где каждой из способностей соответствует определенная творящая Божественная энергия. В настоящей части статьи я приступаю к детальному сравнению учения об иерархии природного сущего у Григория Паламы и в предшествующей патристической литературе - у Дионисия Ареопагита и Григория Нисского. Затем я сделаю очерк рецепции учения Григория Паламы, связанной с темой иерархии сущих, в русской религиозно-философской мысли, в связи с чем я остановлюсь на философии творчества С.Н. Булгакова.

Итак, Палама утверждает, что Бог со Своей стороны причаствуется тварью полностью; умное же тварное сущее со своей стороны может причаствовать к Нему полностью либо частично ${ }^{3}$ в зависимости от расположения воли. Со стороны Бога полнота природной причастности к Нему тварного сущего не зависит от вида или количества видов этой причастности, но природная причастность к Богу хотя бы в каком-то одном отношении подразумевает причастность всему Божеству4. Развивая эту тему, Палама следует Дионисию Ареопагиту ${ }^{5}$.

Ведя речь о порядке звеньев иерархии природно причаствующих, Григорий также следует Ареопагиту. Звенья и их порядок, перечисляемые Паламой: бытийное-живоечувствующее-разумное-умное/мудростное-духовное, в целом соответствуют тому, что имеет место в иерархии у Дионисия: сущее-живое-чувствующее-разумное-умное. Таким образом, иерархия природного сущего у Григория Паламы восходит через Ареопагита, с одной стороны, к неоплатонической триаде Бытие, Жизнь, Ум, определяющей порядок звеньев иерархии природного сущего у Дионисия, а вслед за ним у Григория, а с другой (в отношении расположенного между живым и разумным звена чувствующее), к иерархии, выстраиваемой Григорием Нисским, и через нее к библейско-космогоническому порядку природного сущего.

Однако имеются и определенные отличия между используемым Паламой дискурсом иерархии природно причаствующих и соответствующей темой у Ареопагита.

Так, в отношении того, к чему причаствуют звенья иерархии природного сущего, Палама не следует дискурсу Дионисия: дионисиевские выступления, причаствуемые звеньями иерархии, соответствуют неоплатонической тетраде Благо, Сущее, Жизнь, Ум, в силу чего у Дионисия имеется некоторое расхождение между порядком выступлений и причаствующих к ним звеньев иерархии: он ведет речь о трех выступлениях (Сущем, Жизни и Премудрости), которым соответствуют пять ступеней иерархии природно причаствующих (существующее, живое, чувствующее, разумное и умное). У Паламы же именования и порядок творящих Божественных энергий находится в строгом соответствии со звеньями иерархии природных способностей тварного сущего, которые причаствуют к этим энергиям.

\section{Biriukov 2017.}

3 Cр.: Antirrhetici contra Acindynum V 27.115; Gregorius Palamas 1970, 374-375 и Dialogus inter orthodoxum et Barlaamitam 46-47; Gregorius Palamas 1994, 209-210.

4 Antirrhetici contra Acindynum V 27.116: 20-21; Gregorius Palamas 1970, 375-376.

5 De divinis nominibus II, 5. 
Также, у Паламы в перечне природных способностей, посредством которых тварное

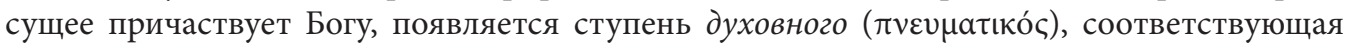
природной причастности, свойственной для ангельских сил. У Дионисия же ангельские силы причаствуют Божеству посредством умной способности. То есть у Паламы по сравнению с Дионисием имеет место частичное смещение природных способностей по отношению к видам обладающих ими существ: у Дионисия умная способность в иерархии природно причаствующих характерна для ангельских (умных) сил, тогда как для человеческого существа характерной является разумная способность ${ }^{6}$, по Паламе же для человека является свойственной умная способность, тогда как для ангельских сил духовная природная способность.

Еще одно различие между Дионисием Ареопагитом и Григорием Паламой состоит в том, что у последнего тема иерархии природно причаствующих жестко связана с темой сверхприродной причастности. Можно сказать, что сама тематика иерархии природно причаствующих сущих и появляется у Паламы, чтобы прояснить отличие обожения как сверхприродной причастности Божеству от природной причастности всего сущего Богу. И потому речь об иерархии природно причаствующих у Григория Паламы почти всегда соединяется и оттеняется учением о сверхприродной причастности обоживаемых людей Божеству. То есть наивысшим элементом иерархии причастности для тварного сущего уже не только природной причастности, но также и сверхприродной - у Паламы выступает обоживающая причастность, каковой соответствует причаствуемая боготворящая Божественная энергия ${ }^{7}$.

Дионисий же, хотя и говорит о начале Само-Божества, как и о соответствующим причаствующем ему обоженном сущем, упоминает об этом начале в числе других начал с приставкой Само- ${ }^{8}$, не выделяя и не встраивая его в учение об иерархии причаствующих.

Из рассмотренных мною в этой серии статей авторов, предшествующих Паламе, тема обожения возникала в контексте иерархии сущего только у Григория Нисского, однако в рамках его совсем иного понимания механизма и структуры иерархии, чем понимание, представленное у Паламы. Следует отметить противоположность используемого Григорием Нисским и Григорием Паламой понятийного аппарата для указания на концепт обоживающей причастности к Богу в рамках темы иерархии причаствующих. Тогда как Григорий Нисский использует для этого концепт причастности к Божественной природе9, в доктрине Паламы он запрещен, и в рамках его богословской системы обоживающая причастность понимается как причастность не к Божественной природе, но к нетварной энергии Божества. Это связано с противоположными парадигмами причастности, используемыми Григорием Нисским и Григорием Паламой. А именно, Григорий Нисский, когда учит о причаствуемости Божественной природы святыми людьми, использует парадигму, которую я называю платонической парадигмой причастности в патристике, предполагающую, что нечто причаствующее природе чего-то не становится в силу этой причастности той же природы, что причаствуемое. Тогда как Григорий Палама в своем

6 De divinis nominibus V, 3; Pseudo-Dionysius Areopagita 1990, 182. См.: Perl 2007, 70-71.

См. особенно: Antirrhetici contra Acindynum V 27.116; Gregorius Palamas 1970, 375-376.

8 De divinis nominibus V, 5; Pseudo-Dionysius Areopagita 1990, 183-184 и XI, 6, Pseudo-Dionysius Areopagita 1990, 221-223 См.: Бирюков 2014, 314, 319.

9 См. в целом: Contra Eunomium 1.1.270-277; Gregorius Nyssenus 1960, Т. 1, 105-106, и конкретно о причастности умным тварным сущим нетварной Божественной природы, в зависимости от благости произволения: Contra Eunomium 1.1.274.1-4; Gregorius Nyssenus 1960, T. 1, 106. 
богословском языке использует введенную в патристику Ареопагитом неоплатоническую парадигму причастности, предполагающую различение в Боге непричаствуемого и причаствуемого, и вслед за Максимом Исповедником ${ }^{10}$ относит непричаствуемость к Божественной сущности ${ }^{11}$. В силу этого система Григория подразумевает обоживающую причастность к Богу как причастность к нетварной Божественной энергии, а не к Божественной природе, как это имело место у Григория Нисского.

Итак, существенным моментом учения Григория Паламы об иерархии причаствующих является его позиция относительно того, $\kappa$ чему причаствуют иерархически организованные виды тварного сущего. Базовое положение учения Паламы состоит в том, что они причаствуют к нетварным Божественным энергиям, а именно, природно причаствуют к творящим энергиям и сверхприродно - к боготворящей энергии. Согласно Паламе, эти энергии суть Божество; при этом они отличны от Божественной сущности и различаются между собой. То есть можно сказать, что звенья иерархии природно причаствующих, согласно паламитской парадигме, причаствуют к неким универсальным началам в Божестве. Думать, что сами причаствуемые начала в рамках паламитского учения образуют между собой иерархию, аналогичную иерархии того, что к ним причаствует, у нас нет оснований.

Таким образом, тема иерархии сущего выявляет как существенные отличия, так и схожесть в определенном отношении в богословском языке Григория Нисского, Дионисия Ареопагита и Григория Паламы. Иерархия тварного сущего у Григория Нисского не предполагает соответствующих звеньям иерархии трансцендентных начал, к которым эти звенья причаствуют, в то время как иерархии Дионисия Ареопагита и Григория Паламы предполагают это. В то же время, хотя Палама во многом следует Дионисию, в его иерархии имеет место звено, соответствующее состоянию обожения, чего нет в иерархии сущего у Дионисия. Однако в этом отношении - в плане наличия звена в иерархиях сущего, отвечающего за обожение - имеется сходство между иерархиями у Григория Паламы и Григория Нисского, хотя и богословский язык, используемый для выражения обожения в контексте темы иерархий у них противоположный: Григорий Нисский использует язык причастности к Божественной природе (сущности), Григорий Палама же, отрицая этот язык, учит о причастности к боготворящей Божественной энергии.

\section{Иерархия сущего в учении Давида Дисипата}

Интересное преломление тема иерархии сущего в рамках паламитской литературы находит также в Ямбах против Акиндина (2-я пол. 1343 г.) ${ }^{12}$, написанных другом Григория Паламы

10 Quaestiones et dubia 173.1-7; Maximus Confessor 1982, 120 и Capita theologica et oeconomica, PG 90, 1180C-1181A.

11 Учение о совершенной непричаствуемости Божественной сущности для тварного сущего представляет собой сквозную линию в текстах Паламы, и речь об этом встречается у него очень часто. Однако имеются единичные случаи смягчения Григорием этой линии: в диалоге Феофан от лица одного из собеседников (Феофана) он утверждает в 13-й гл., что хотя сущность Божия непричаствуема, но неким образом она и причаствуема (Gregorius Palamas 1994, 238.7-10), а в 17-й гл. - что Божественная природа причаствуема, хотя и не сама по себе, но через свои энергии (Gregorius Palamas 1994, 243.20-24); см. также у Давида Дисипата: Carmen contra Gregorium Acindynum: Browning 1955-1957, 447-448.

12 David Dishypatus. Carmen contra Gregorium Acindynum: Browning 1955-1957, 453-493. 
монахом Давидом Дисипатом, который, как и Палама, развивал эту тему в качестве антитезы к учению Акиндина.

У Дисипата паламитская тема природной и сверхприродной причастности к Божественным энергиям формулируется следующим образом. С одной стороны, все тварное сущее природно причаствует Богу через благодать (Божественные энергии) как своему Твориу (причастность по сотворенности). В этом отношении Богу-Творцу причастны и люди, как разумные существа, и в частности, те из них, которые используют свою способность разума растленно и противятся Богу. Другой способ причастности к Богу - уже не как к Творцу, но как к Отцу - возможен для тех людей, которые очистили свою умную природу; они просвещаются вышеразумным Божественным сиянием (энергией) и делаются Богом подобными Себе. Однако ни в одном из способов причастности Божеству не происходит причастности к Божественной сущности. Некоторое терминологическое отличие в рамках богословского языка Дисипата от языка Паламы, кажется, заключается в том, что Дисипат различает причастность всего тварного сущего к Богу как к Творцу и причастность обоживаемых людей к Богу как к Отцу, в то время как Григорий Палама, насколько мне известно, не делает этого различения в именовании Бога как двояко причаствуемого тварным сущим.

У Дисипата обнаруживается также интересная трактовка темы иерархии сущего, отличная от тех, про которые я вел речь выше. Если у Паламы, как и у его предшественников, используется восходящая через Ареопагита к философии Прокла парадигма, предполагающая ограниченное количество причаствующих природных способностей, то дискурс Дисипата подразумевает отход от этой парадигмы. Дисипат пишет о причастности тварного сущего к Богу:

Но может быть различное причастие,

Поскольку есть в природах различение:

Имеются совсем души лишенные,

Есть те, что возрастают на питании,

Есть те, что также и умеют чувствовать,

Но лишены способности к движению,

Иные бегают, летают, плавают,

А мы наделены и даром разума.

И каждое из них до беспредельности

Мы снова разделяем нашим разумом

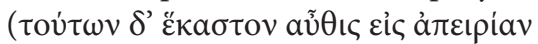

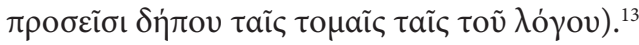

Говоря о различных природах тварного сущего, Дисипат упоминает о неодушевленном, питающемся, бездвинном чувствующем, чувствующем способным двигаться и разумном. Этот перечень отличается от стандартного перечня звеньев иерархии природно причаствующего тварного сущего, представленного у рассмотренных нами патристических авторов от Дионисия до Паламы. Он восходит к Аристотелю ${ }^{14}$, но возможно Дисипат в этом отношении опирался и на какую-то естественнонаучную традицию его времени.

Итак, Дисипат выделяет множество природных способностей, по которым тварное сущее может причаствовать к Творцу в аспекте Божественных энергий, и в конце

13 Там же: Browning 1955-1957, 465-474, пер. 3.А. Барзах и А.В. Маркова.

14 Aristotle, De anima II, 3, 414a29ff. 
концов он говорит, что мы можем до беспредельности различать такие способности внутри имеющихся. При этом нельзя сказать с уверенностью, относится ли это только к гносеологическому порядку, как возможности беспрерывно различать разумом новые и новые различия в тварном сущем, при том что для самого тварного сущего эта беспредельность различений не является характерной ${ }^{15}$, или же согласно Дисипату эта беспредельность имеет также и онтологический смысл, как беспредельность различия видов сущего в рамках природы согласно их природным свойствам.

\section{Рецепция паламизма в русской религиозной мысли XX в. (философия творчества С.Н. Булгакова)}

Укажем также на важнейшие аспекты рецепции в русской мысли паламизма и темы иерархии сущего в паламитском учении.

О начале рецепции паламизма в русской мысли можно говорить со времени появления трактата «Апология веры во Имя Божие и во Имя Иисус», написанного иеросхимонахом Антонием (Булатовичем) в рамках так называемых имяславских споров. «Апология» была закончена Булатовичем в июле 1912 г. и опубликована в 1913 г. Напомню, что представители имяславского движения утверждали, что христианин, мысля о Боге и именуя Бога, например, в молитве, приобщается к Самому Богу в Его энергиях, и поэтому имена Бога, мыслимые и нарицаемые человеком, суть сами Божественные энергии, а значит и сам Бог. $\mathrm{B}$ «Апологии» чтобы убедить читателей, что имя Божие есть Бог, в смысле Божественного действия, Булатович проводит характерное для паламизма учение о различении в Боге неименуемой сущности и именуемых божественных действий (энергий), где действия Божества отождествляются с божественными свойствами и понимаются как в собственном смысле слова божественные. Однако отсылок к сочинениям Григория Паламы в этом трактате нет; учение Паламы - в его исихастском измерении - упоминается только в пересказе Паисия Величковского ${ }^{16}$. Это связано с тем, что догматические сочинения Григория Паламы в эпоху имяславской полемики фактически не были переведены на русский язык. При этом в «Апологии» имеются довольно частые отсылки к паламитским спорам, связанные с тем, что Булатович приравнивает позицию своих противников к учению Варлаама Калабрийского.

Интерес к паламизму был подхвачен соратниками Булатовича по защите имяславия П.А. Флоренским и С.Н. Булгаковым. П.А. Флоренский воспринял паламитский язык различения сущности и энергий и стал активно использовать его в своих сочинениях; однако Флоренский фактически не читал сочинений Паламы, и использовал паламитский язык в качестве расхожего дискурса.

15 Из современников Дисипата такая позиция разделялась антипаламитом Никифором Григорой, который в своем трактате «О всецелом и в себе существующем эйдосе, который созерцается одним лишь умом» (Beyer 1971, 183) проводит различие между актуальной беспредельностью Бога и мнимой беспредельностью многообразного тварного мира - эйдосов и их порождений; согласно Григоре, последнее является беспредельным для нас, но не по природе.

16 Источники Булатовича в «Апологии» в отношении конкретных деталей учения Григория Паламы исчерпываются книгой: Paisij Velichkovskij 1892. Эта книга содержит три места с упоминанием имени Григория Паламы, в том числе, одно с анафематствованием Варлаама и Акиндина (в исихастском, а не догматическом контексте). Ни одно из этих мест не содержит паламитского учения о различении в Боге сущности и энергий, но каждое упоминает имя Паламы лишь в связи с исихастским измерением его мысли, т.е. в связи с учением об умной молитве. 
Как кажется, первым автором в русской религиозно-философской мысли, обратившимся к текстам Паламы, был С.Н. Булгаков. Как мне представляется, период активного изучения Булгаковым наследия Паламы приходится на 1914-1916 гг. - время, предшествуюее написанию им сочинения «Свет Невечерний», изданного в 1917 г. В этом сочинении в контексте своих рассуждений Булгаков использует изученные им тексты Паламы, и приводит цитаты из сочинений Паламы - вероятно, в своем собственном переводе.

В дальнейшем же Булгаков будет апеллировать к Паламе и паламизму: он будет делать это, в основном, в контексте разработки софиологических идей и полемики с критиками его софиологии ${ }^{17}$. Однако его отсылки к паламизму и сочинениям Паламы уже будут общего характера, без цитат и почти без отсылок к конкретным текстам.

Интерес Булгакова к сочинениям Паламы проявляется уже в его переписке с Флоренским, относящейся к 1914 г. В письме от 15 февраля 1914 г. Булгаков свидетельствует, что он «занимается Паламой» и думает о своевременности издания русских переводов трактатов византийского богослова. Из них Булгаков в этом письме выделяет трактаты Cто пятьдесят глав и Феофан, перевод и издание которых особенно необходимы ${ }^{18}$. В Свете Невечернем мы обнаруживаем уже следы детального чтения Булгаковым сочинений Паламы, а конкретно - трактатов «150 глав» и «Феофан», упомянутых в письме Булгакова к Флоренскому. Учение Григория Паламы обсуждается в этом сочинении трижды. Во-первых, в отделе, посвященном Божественному ничто, - здесь Булгаков обсуждает различение Григорием Паламой в Божестве «трансцендентной сущности», каковая «характеризуется чертами отрицательного богословия», и энергий, в каковых Бог «осуществляет Себя». Иллюстрируя это учение, Булгаков приводит цитаты из трактатов Паламы Феофан и Сто пятьдесят глав ${ }^{19}$ (везде в Свете Невечернем Булгаков приводит цитаты из Паламы по 150-му тому патрологии Миня (PG 150)).

Во-вторых, в разделе своего сочинения, посвященном Софии, Булгаков упоминает учение Паламы в связи со своей доктриной Софии как Души мира (в которое мы здесь не будем углубляться). В этом плане Булгаков - хоть это и расходится с его целью утвердить в церковном сознании учение о Софии - указывает на полемику Паламы с «языческой» доктриной Мировой Души, о каковой он узнал, очевидно, штудируя трактат Паламы Сто пятьдесят глав. Булгаков приводит место из Ста пятидесяти глав, где говорится о том, что не существует никакой небесной или всемирной разумной души, но есть только единственный вид души - это человеческая душа ${ }^{20}$.

Наконец, в разделе, обсуждающем различие между человеческим и ангельским существом, относящемся к отделу «Человек», Булгаков приводит цитаты из «150 глав» Григория Паламы, иллюстрирующие это различие. Из них следует, что человек, будучи, в отличие от ангелов, сотворенным из материи, получил от Бога оживляющий эту материю дух, сохраняющий и оживотворяющий человеческое тело. Человека отличает от ангела наличие этого духа (PG 150, col. 1147); так же как и свойственная человеческой душе способность начальствовать - над страстями, телом и всей землею (PG 150, col. 1165).

Ключевой является следующая цитата Ста пятидесяти глав Паламы, PG 150, col. 1165, приводимая Булгаковым:

17 Обзор мест из сочинений и корреспонденции Булгакова с упоминанием Григория Паламы или паламизма см. в работах: Angelov - Pavlov - Tanev 2017, 58-71; Vaganova 2010, 108-111.

18 Florenskij - Bulgakov 2001, 78.

19 Bulgakov 1994, 111-113.

20 Bulgakov 1994, 196, прим. * 
[Люди] одни из тварей, кроме способности к разуму и слову, имеют еще чувственность [курсив С.Н. Булгакова. - Д.Б.], которая, будучи по природе соединена с умом, изобретает многоразличное множество искусств, умений и знаний: занятие земледелием, строение домов и творчество из не-сущего ( $л \rho о \alpha ́ \gamma \varepsilon เ v$

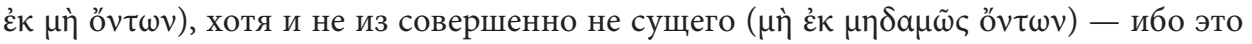
принадлежит лишь Богу - свойственно одному лишь человеку... Ничего из этого ни в каком смысле не свойственно ангелам.

Нетрудно определить, что это место представляет собой 63-ю главку из Ста пятидесяти глав; по современному изданию данного трактата Р. Синкевичем это следующее место: Saint Gregory Palamas 1988, 156. Если мы посмотрим на греческий текст следующей фразы из этого фрагмента в переводе С.Н. Булгакова: «[люди] ...кроме способности к разуму

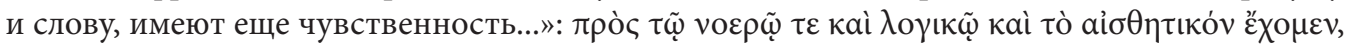
мы увидим, что здесь находит свое проявление учение Григория Паламы об иерархии способностей человеческого существа, о котором шла речь в первой части настоящей

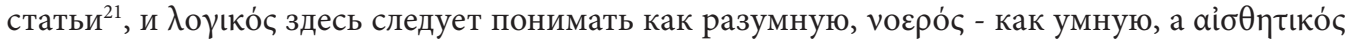
как чувствующую способность человеческого существа. Таким образом, корректный перевод этой фразы должен звучать так: «[люди] ...кроме ума и разумности, обладают еще и чувствующей способностью».

Булгаков комментирует сказанное Паламой в этом фрагменте следующим образом: «В число отличий между человеком и ангелом св. Григорий включает и способность к хозяйству, к хозяйственному владению землей, свойственную только человеку» ${ }^{22}$. Отсылка к теме хозяйства у Булгакова здесь появляется не случайно. Философия хозяйства - центральная тема философского творчества Булгакова периода 1906 - 1912 гг. Содержание этого фрагмента из Паламы имеет отношение к теме, которой Булгаков касался в своей предыдущей, по отношению к Свету Невечернему, фундаментальной работе Философия хозяйства, изданной в 1912 г. А именно, это тема творчества (при всей разности коннотаций концепта творчества для Паламы и Булгакова). Хотя в комментарии Булгакова на вышеприведенный фрагмент из Паламы эта тема не акцентируется, она является важной как для «Философии хозяйства», так и для «Света Невечернего».

Тому, что Булгаков перевел как «творчество» в этом фрагменте из Паламы, в оригинальном тексте Паламы соответствует глагол прод́ $\varepsilon є v$, что буквально значит «вывести наружу». То есть буквально у Паламы говорится: «выведение из не-сущего»; но контекст этой фразы - сравнение соответствующей способности человека с Божественным актом выведения тварного из совершенно не-сущего (творением из ничего) - указывает, что смысл, заложенный в этой фразе Паламы, можно передать и через понятие «творчества», как это сделал Булгаков. Однако можно сказать, что выбор Булгаковым слова «творчество»

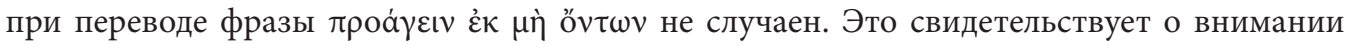
Булгакова к философии творчества - внимании, проявляющемся и когда он работает с текстами Паламы.

В Философии хозяйства Булгаков так же, как и Палама, соотносит человеческое творчество с мифологемой божественного творения из ничего. Однако взгляд Булгакова на метафизический статус творчества в Философии хозяйства гораздо менее позитивен, чем взгляд Григория Паламы в Ста пятидесяти главах. Палама говорит о человеческом

21 Biriukov 2017, 20.

22 Bulgakov 1994, 268. 
творчестве как о том, что из не-сущего, хотя и не из совершенно не-сущего - последнее возможно только для Бога в Его творческом акте. Таким образом, творчество человеческого существа, как соединяющего в себе чувствующую и умную способности, согласно Паламе, по своей природе подобно Божественному творению из ничто; первое соответствует последнему, взятому в человеческой мере. Булгаков же в Философии хозяйства противопоставляет и сталкивает человеческое творчество и мифологему Божественного творения из ничто. Он настаивает, что человек не может сотворить ничего метафизически нового, каковое возможно только для Бога-Творца, но человеческое творчество есть воспроизведение уже заданных образцов. Подражание же творческому самостоянию Творца есть сатанизм. Творчество соответствует не образу Божию в человеке, который дан, а подобию, которое задано. Человеческое творчество понимается Булгаковым здесь как приобретение знания в платоновском смысле: а именно, приобретение знания через припоминание ${ }^{23}$.

В изданном же через пять лет после Философии хозяйства Свете Невечернем, где, как я говорил, находит свое проявление знакомство Булгакова с идеями Паламы, мы обнаруживаем несколько иное осмысление метафизического статуса творчества. В том же самом отделе «Человек», где он приводит иллюстрирующую различие между человеческим и ангельским существом цитату из Паламы, но несколько ранее, Булгаков рассуждает и о творчестве. Но он делает это уже в несколько ином ключе, чем в Философии хозяйства. Творческую способность в человеке Булгаков здесь относит не к подобию, но к образу Божиему. Он говорит, что человеку свойственно стремление к абсолютному творчеству. Хотя эта абсолютность человеческого творчества всегда остается потенциальной, поскольку творческий продукт, созданный конечным человеком, никогда не исчерпывает творческое выхождение духа. Булгаков говорит о соотношении абсолютного творчества (свойственного для Бога) и человеческого творчества так, что между ними существуют сродство и соотносительность, но при этом и бездна, отличающая потенциальность от актуальности; это бездна является причиной трагичности, внутренне присущей творчеству ${ }^{24}$.

Итак, как мне представляется, философия творчества Булгакова, представленная в «Свете Невечернем», отличается от его же взгляда на творчество в «Философии хозяйства». В последнем случае предполагается, что нет ничего общего между абсолютным Божественным творчеством/творением из ничто, предполагающим метафизическую новизну, и творчеством человеческим, каковое сводится к воспроизведению заданных образцов. В «Свете Невечернем» же Божественное абсолютное творчество понимается как основа для творчества человеческого, образец, хотя и принципиально не достижимый; вследствие чего о Божественном и человеческом творчестве говорится как о соотносительных. Этот взгляд Булгакова на концепт творчества, представленный в отделе «Человек» «Света Невечернего», близок к тому пониманию, которое высказывает Палама в «Ста пятидесяти главах», где также идет речь о человеческом творчестве, понимаемым по аналогии с Божественным творчеством/творением из ничего - во фрагменте, приводимом Булгаковым в том же отделе «Света Невечернего» немного далее. Рассуждение Булгакова о творчестве в «Свете Невечернем» могло бы быть комментарием к соответствующему фрагменту из Паламы - настолько мысли Паламы и Булгакова изоморфны.

23 Bulgakov 2009, 178-179.

24 Bulgakov 1994, 243-244. 
На указанное рассуждение Булгакова о творчестве в Свете Невечернем могла повлиять философия творчества Н.А. Бердяева, о которой он упоминает в ходе своих рассуждений ${ }^{25}$. Однако, как следует из вышесказанного, соответствующее рассуждение Григория Паламы также могло служить источником вдохновения Булгакова в этом отношении.

\section{REFERENCES}

Angelov, Angel - Pavlov Pavel - Tanev Stoyan. 2010. The Sophiological controversy as a clash of different patristic interpretations. In Sophia. The Wisdom of God - Die Weisheit Gottes. Forscher aus dem Osten und Westen Europas an den Quellen des gemeinsamen Glaubens, Herausgegeben von T. Haintaler, F. Mali, G. Emmenegger, M. Ostermann. Innsbruck-Wien.

Biriukov, Dmitri Sergeevitch. 2014. Иерархии сущего в патристической мысли. Григорий Нисский и Дионисий Ареопагит [Hierarchy of beings in the Patristic thought: Gregory of Nyssa and Dionysius the Areopagite]. In Государство, религия, церковь в России и за рубежом [State, Religion and Church in Russia and Worldwide] 32/3, 304-326.

Biriukov, Dmitri Sergeevitch. 2017. Тема иерархии природного сущего в паламитской литературе. Ч. 1. Предыстория темы иерархии сущего и возникновение этой темы в паламитских спорах [Taxonomies of Beings in the Palamite Literature. Part 1. Early History of the Topic of Taxonomy of Beings and Appearance of This Topic in the Palamite Controversy] In Konštantínove listy [Constantine's Letters] 2/10, 15-22.

Bulgakov, Sergei Nikolaevitch. 1994. Свет Невечерний. Созерцания и умозрения [Not evening's light. Contemplation and speculation.]. Moscow.

Bulgakov, Sergei Nikolaevitch. 2009. Философия хозяйства [Philosophy of economy]. Moscow.

Beyer, Hans-Veit. 1971. Nikephoros Gregoras als Theologe und sein erstes Auftreten gegen die Hesychasten. In Jahrbuch der Österreichischen Byzantinistik 20, 171-189.

Browning, Robert. 1955 - 1957. David Dishypatos' Poem on Akindynos. In Byzantion 25-27,

713-745.

Costache, Doru. 2011. 'Experiencing the Divine Life: Levels of Participation in St Gregory Palamas' on the Divine and Deifying Participation. In Phronesis 26/1, 9-25.

Florenskij, Pavel - Bulgakov, Sergij. 2001. Переписка священника Павла Александровича Флоренского со священником Сергеем Николаевичем Булгаковым [Correspondence between priest Pavel Alexandrovich Florensky and priest Sergei Nikolaevich Bulgakov]. Tomsk.

Gregorius Nyssenus. 1960. Gregorii Nysseni opera. Contra Eunomium Libri: I et II. Vol. 1-2. Leiden.

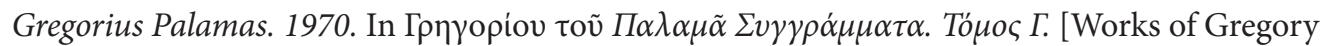

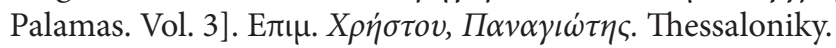

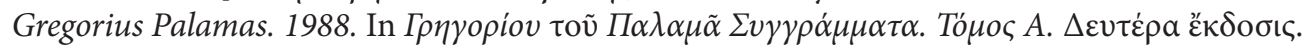

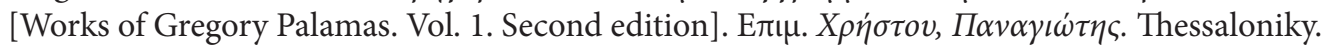

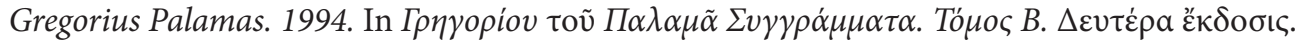

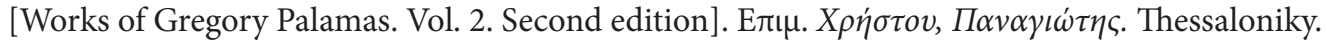
Maximus Confessor. 1982. Declerck, Jose (ed.). Maximi Confessoris Quaestiones et Dubia.

Brepols-Turnhout.

Paisij Velichkovskij. 1892. Житие и писания молдавского старца Паисия Величковского с присовокуплением предисловий на книги св. Григория Синаита, Филофея Синайского,

25 Bulgakov 1994, 244. 
Исихия пресвитера и Нила Сорского, сочиненных другом его и спостником старцем Василием Поляномерулским, об умном трезвении и молитве [The life and writings of the Moldavian elder Paisius Velichkovsky with addition of his preambles to the books of St Gregory the Sinaite, Philotheus of Sinai, Hesychius the Presbyter and Neilus of Sorbia Sorbara composed by his friend elder Basil of Polynomerula, about sobriety and prayer]. Moscow.

Perl, Eric. 2007. Theophany: the Neoplatonic philosophy of Dionysius the Areopagite. New-York. Saint Gregory Palamas 1988. The One Hundred And Fifty Chapters. Sinkewicz, Robert, a critical edition, translation and study. A Critical Edition, Translation and Study. (Studies and Texts 83). Toronto.

Perl, Eric. 2007. Theophany: the Neoplatonic philosophy of Dionysius the Areopagite. New-York. Pseudo-Dionysius Areopagita. 1990. De divinis nominibus. In Suchla, Beate Regina (ed.). Corpus Dionysiacum 1. Berlin.

Vaganova, Natalia. 2010. Софиология протоиерея Сергия Булгакова [Sophiology of Archpriest Sergius Bulgakov]. Moscow.

\begin{abstract}
SUMMARY: TAXONOMIES OF BEINGS IN THE PALAMITE LITERATURE. PART 2. THE PALAMITE DOCTRINE IN THE CONTEXT OF THE PREVIOUS BYZANTINE TRADITION AND ITS RECEPTION IN THE RUSSIAN RELIGIOUS THOUGHT OF THE XXth CENTURY (THE PHILOSOPHY OF CREATIVITY BY SERGEI BULGAKOV). I provide a detailed comparison of the doctrine of taxonomy of beings in Gregory Palamas and such previous Byzantine theologians as Dionysius the Areopagite and Gregory of Nyssa. I examine David Dishypatos' teaching on taxonomy of beings as well. The study shows that Palamas partly shifted natural abilities in relation to the kinds of created beings which possess them compared to Dionysius: in the Dionysian hierarchy of naturally participating beings, intellectual ability was typical for the angelic (intellectual) powers, while rational ability was typical for the humans. In Palamas, intellectual ability was typical for the humans, while spiritual natural ability was typical for the angelic powers. I observe the reception of Gregory Palamas' teaching of taxonomy of beings in Russian religious and philosophical thought. In this regard, I consider Sergei Bulgakov's philosophy of creativity. I believe that the fragment from Palamas' "The One Hundred and Fifty Chapters" (PG 150, col. 1165 = Saint Gregory Palamas. The One Hundred And Fifty Chapters. Sinkewicz, Robert, a critical edition, translation and study. Toronto, 1988. P. 156) was essential for the formation of philosophy of creativity offered by Bulgakov in his "Unfading Light. Contemplations and Speculations". In addition, I offer revisions of Bulgakov's translation of this Palamas' fragment.
\end{abstract}

Dr habil Dmitry Biriukov, PhD.

The Sociological institute of the Russian Academy of Science, National Research University Higher School of Economics (HSE),

Saint Petersburg State University of Aerospace Instrumentation (SUAI)

Severny av., 6/1, 536

194354 St Petersburg

Russia

dbiryukov@hse.ru 